JUSTYNA KOBUS

Instytut Filologii Polskiej

Uniwersytet im. Adama Mickiewicza w Poznaniu

\title{
NAZWY DAWNEGO DREWNIANEGO PRZYRZĄDU DO ZDEJMOWANIA BUTÓW Z CHOLEWAMI \\ 30 LAT PO ATLASIE JEZZYKA I KULTURY LUDOWEJ WIELKOPOLSKI (NA PRZYKŁADACH Z WYBRANYCH WSI WIELKOPOLSKICH)
}

Dialektologiczne badania terenowe bardzo często uzmysławiają zarówno badającemu, jak i osobie badanej, jak bardzo zmienia się nasze otoczenie. Szczególnie znamienne staje się to podczas pytań o desygnaty dawne, od lat zalegające na strychach lub w szopach. Niejednokrotnie, podczas takich badań, eksplorator wraz z informatorem odnajdują tzw. starocie, które u pierwszego budzą chęć bliższego poznania, a u drugiego przywołują wspomnienia $\mathrm{z}$ lat młodości, a nawet dzieciństwa.

Jednym $\mathrm{z}$ takich przedmiotów jest prostej konstrukcji drewniany przyrząd do zdejmowania butów z cholewami. Składa się on z trójrożnej deski (z mniej lub bardziej zaokrąglonymi końcami) z wycięciem na piętę i poprzecznie przymocowanej u dołu deseczki (podstawki) lub dwóch nóżek, umożliwiających ustawienie deski pod kątem.

Literatura na ten temat nie jest zbyt obszerna. Nazwy przyrządu do zdejmowania butów z cholewami notuje się w Atlasie języka i kultury ludowej Wielkopolski (AJKLW-6: m. 574), Studiach Warmińsko-Mazurskich (Barska-Antos 1980: m. 26) oraz Atlasie gwar ma-


Pies do zdejmowania butów z cholewami, Baranówko 2003 rok (fot. J. Kobus) 
zowieckich (AGM-8: m. 364); natomiast w Atlasie gwar polskich (AGP-2) - na Mazowszu - zapisana została nazwa sobaczka 'pachołek do butów' (m. 165).

Ponadto nazwy 'przyrządu do zdejmowania butów z cholewami' odnaleźć można w niektórych słownikach gwarowych, takich jak: Słownik gwary wsi Podróżna w Złotowskiem (Brzeziński 1987-2009), Słownik warmiński (Steffen 1984), Mały słownik gwar polskich (MSGP 2009), kartoteka Słownika gwar polskich PAN (SGP PAN 1977-2013), kartoteka Stownika gwar śląskich (SGŚ 2000-2012) przy Instytucie Śląskim w Opolu, kartoteka Adama Tomaszewskiego (Pracownia Dialektologiczna UAM), Co wieś, to inna pieśń. Słownik gwary Bukówca Górnego w Wielkopolsce i regionu Spisza w Małopolsce (Dragan i in. 2014), Mój słownik gwary pałuckiej (Binkowski 2011).

W artykule chcę prześledzić, jakie zmiany zaszły w świadomości współczesnych mieszkańców wsi w zakresie znajomości nazwy i desygnatu oraz jak dane te mają się do wyników wcześniejszych badań, tj. opublikowanych głównie w AJKLW-6 (oraz w innych źródłach dotyczących Wielkopolski). Warto zauważyć, że badania atlasowe prowadzone były w latach 70. i 80., zatem ponad 30 lat temu. Z tej perspektywy badania współczesne nabierają charakteru badań monitorujących stan zachowania w języku mieszkańców wsi konkretnych nazw. Z tego też względu niniejszy artykuł wpisuje się w prowadzony w ośrodku poznańskim cykl badawczy 30 lat po Atlasie języka i kultury ludowej Wielkopolski.

Materiał współczesny pozyskany został od zróżnicowanych pod względem pokoleniowym informatorów ${ }^{1}$. Przywoływane przykłady pochodzą z materiałów zebranych samodzielnie oraz zdeponowanych w Pracowni Dialektologicznej UAM. Większość wykorzystanych w artykule tekstów pozyskano drogą rozmowy na podstawie kwestionariusza tematycznego autorstwa Jerzego Sierociuka ${ }^{2}$, rozmowy były nagrywane, a następnie transkrybowane zgodnie z zasadami przyjętymi w Pracowni Dialektologicznej UAM w Poznaniu. Badania uzupełniające w jednym punkcie badawczym przeprowadzono metodą korespondencyjną. Ponieważ we wstępnie wytypowanym punkcie badawczym (tj. Adamów, gm. Golina, pow. Konin) badania terenowe okazały się niewystarczające, postanowiłam przeprowadzić wśród okolicznej ludności ankietę, w której zawarte było pytanie „Jak się mówi na drewniany przedmiot służący niegdyś do zdejmowania butów z cholewami?" oraz rycina z desygnatem i pola do wypełnienia danych dotyczących informatora (imię i nazwisko, miejscowość, ile lat informator zamieszkuje daną wieś) ${ }^{3}$. Najwięcej odpowiedzi uzyskano w miejscowości Spławie (gm. Golina, pow. Konin), która to nazwa w opisie będzie oznaczała punkt badawczy obejmujący zbiór wsi, z których pozyskałam wypełnione ankiety (są to bowiem miejscowości położone od siebie w bardzo bliskiej odległości) oraz badaną wcześniej wieś Adamów. Zatem punkt Spławie w niniejszym artykule obejmuje następujące miejscowości położone w gminie Golina: Adamów, Lubiecz, Kolonia Golina, Spławie.

1 J. Sierociuk wyróżnił następujące grupy informatorów: I. ur. przed rokiem 1920, II. ur. w latach 1921-1945, III. ur. w latach 1946-1970, IV. ur. w latach 1971-1995, V. ur. w roku 1996 i później (S i e r o c i u k 2003: 134).

2 J. S i e r o c i u k, Kwestionariusz do badania słownictwa gwarowego. IV. Praca (wersja elektroniczna dostępna w Pracowni Dialektologicznej UAM).

${ }^{3}$ Do przeprowadzenia ankiety zaangażował się Przemysław Ciesielski, nauczyciel języka polskiego i historii ze Szkoły Podstawowej im. Juliusza Słowackiego w Golinie. 


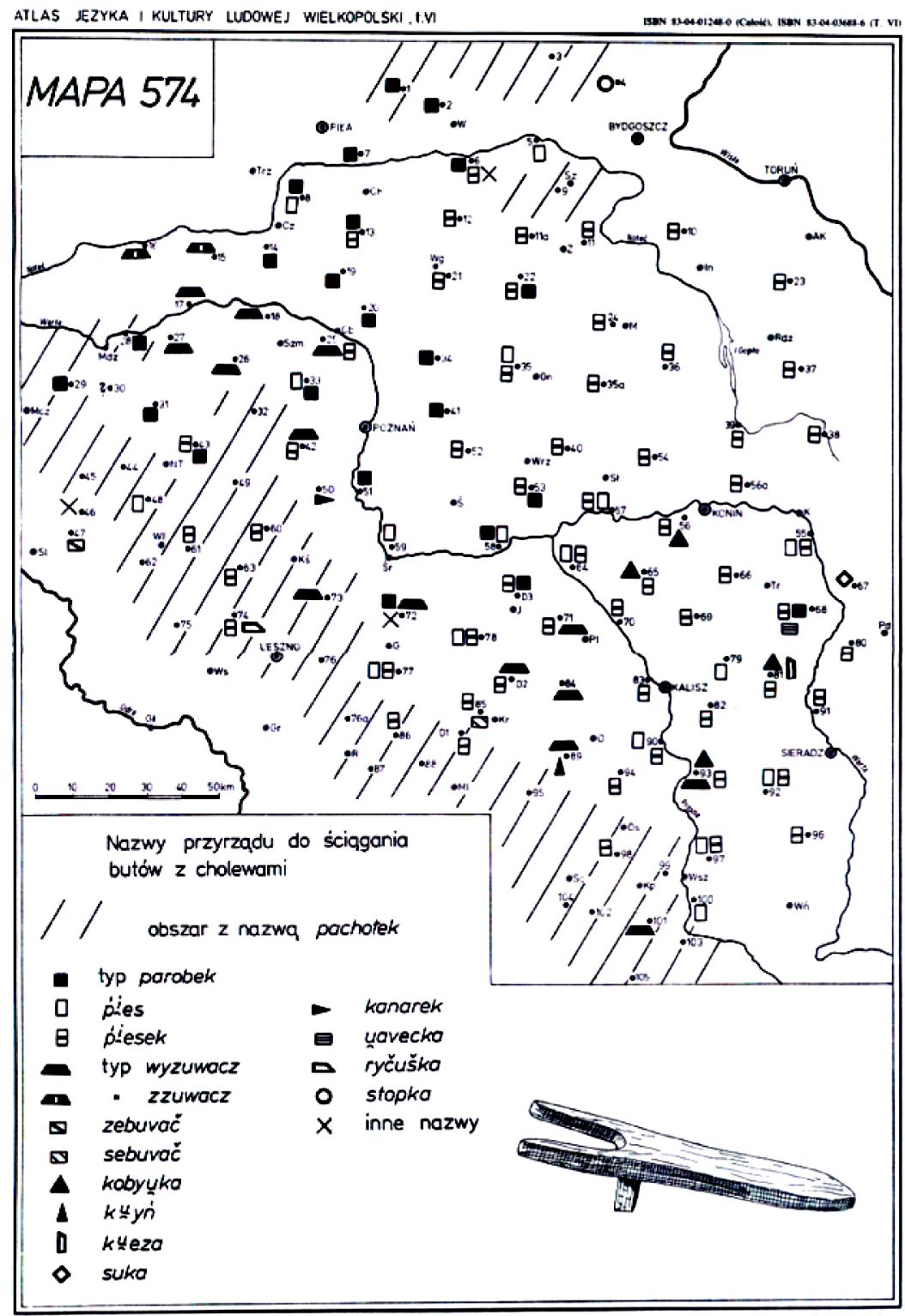

Punktami badawczymi są: Jaryszewo (gm. Szamotuły, pow. Poznań), Baranówko i Sowinki (traktowane jako jeden punkt badawczy z uwagi na dzielącą je wyłącznie granicę administracyjną, gm. Mosina, pow. Poznań), Spławie (gm. Golina, pow. Konin), Bukówiec Górny (gm. Włoszakowice, pow. Leszno), Krzyszczewo (gm. i pow. Gniezno). Miejscowościom tym odpowiadają następujące punkty AJKLW: Słopanowo-Kobylniki (gm. Obrzycko, pow. Szamotuły) - p. 18 (okolice Jaryszewa), Rogalinek-Sasinowo (gm. Mosina, pow. Poznań) - p. 51 (okolice Baranówka i Sowinek), Sławsk-Branno (gm. Rzgów, pow. Konin) 
- p. 56 (okolice Spławia), Obora (gm. i pow. Gniezno) - p. 35 (okolice Krzyszczewa), natomiast Bukówiec Górny jest jednocześnie punktem atlasowym - p. 74.

Informatorzy z poszczególnych punktów badawczych to: Jaryszewo - $[\mathrm{NoH}]$ - mężczyzna ur. 1931; Baranówko i Sowinki: p. II - [MiZ] - mężczyzna ur. 1926, [RaA] - mężczyzna ur. 1931; p. III - [MiJ] - mężczyzna ur. 1964, [MiG] - kobieta, ur. 1966; Spławie: p. II - [AnC] - mężczyzna ur. 1928, [SzW] - kobieta ur. 1930, [ChG] - mężczyzna ur. 1939; p. III - [RoD] - kobieta ur. 1958, [WeB] - mężczyzna ur. 1962, [PłD] - kobieta ur. 1964; Krzyszczewo: p II: [SzAl] - mężczyzna ur. 1927, [SzZ] - kobieta ur. 1936; p. III - [SzA] - mężczyzna ur. 1966; Bukówiec Górny: p. II - [SzA] - kobieta ur. 1923, [SzJ] - mężczyzna ur. 1925, [MłP] - kobieta ur. 1929, [ŚlZ] - kobieta ur. 1934; p. III - [GuB] - mężczyzna ur. 1946, [BaK] - kobieta ur. 1947, [MaM] - kobieta, ur. 1948. Jest to niewielka próba badawcza, lecz wystarczająca dla stwierdzenia obecności danej nazwy i desygnatu w świadomości użytkowników języka wsi.

Jako punkt wyjścia do analiz przyjmuję dane zawarte w AJKLW-6.

AJKLW-6: m. 574 Nazwy przyrządu do ściągania butów z cholewami

W AJKLW-6 odnotowano 15 podstawowych nazw (w tym typów nazw) - zob. mapa

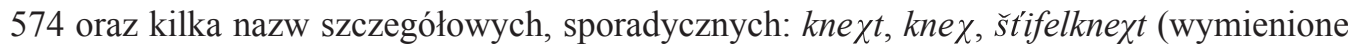
w komentarzu do mapy ${ }^{4}$ ).

Niżej podaję nazwy 'przyrządu do zdejmowania butów z cholewami’ pozyskane współcześnie w wymienionych wyżej miejscowościach; zarazem przytaczam nazwy dla danego punktu lub jego okolicy zapisane w AJKLW:

Jaryszewo: drajfus, wyzuwacz [NoH] - AJKLW-6, p. 18: typ wyzuwacz;

Baranówko i Sowinki: pies [MiZ], pomocnik [MiZ], szczudta [RaA] - AJKLW-6, p. 51: typ parobek;

Spławie: pies $[\mathrm{SzW}][\mathrm{CzA}][\mathrm{ChG}]$, piesek $[\mathrm{RoD}],[\mathrm{WeB}],[\mathrm{PłD}]$, koziołek $[?]^{5}-$ AJKLW-6, p. 56: ṕiesek, kobyuka;

Krzyszczewo: piesek [SzA], [SzZ] - AJKLW-6, p. 35: pies, ṕiesek;

Bukówiec Górny: pies [SzA], [MłP], [SzJ], piesek [GuB], koń [ŚlZ], deska [SzA] AJKLW-6, p. 74: ṕiesek, ryčuška.

Porównując nazwy zebrane $\mathrm{w}$ ostatnim dziesięcioleciu z danymi o charakterze archiwalnym, łatwo dostrzec, że część nazw dawnych nadal funkcjonuje w języku współczesnych mieszkańców wielkopolskich wsi. Z reguły nazwy te pochodzą z zasobu słownictwa biernego (sytuacja dość typowa podczas rozmowy na tematy odległe od współczesności).

Przyjrzyjmy się uważniej materiałom pozyskanym współcześnie w terenie.

Najczęściej notowanymi nazwami są pies i piesek. Zapisano je w następujących punktach: pies w Baranówku i Sowinkach, Spławiu, Bukówcu Górnym, natomiast piesek pojawił się w Spławiu, Bukówcu Górnym i Krzyszczewie.

Nazwa pies okazała się dla najstarszego informatora z Baranówka dobrze znana. Mimo że większość dostępnych słowników jej nie potwierdza, to w terenie jest ona stosunkowo często poświadczana. W wypowiedziach mieszkańców Bukówca Górnego z największą

\footnotetext{
${ }^{4}$ Kom. 6-2, s. 113.

${ }^{5}$ Ankietowana osoba nie wpisała roku urodzenia, trudno więc określić, z którego przedziału pokoleniowego pochodzi. Próba dotarcia do tej informacji nie powiodła się.
} 
częstotliwością pojawiała się nazwa pies, a atlasowy ṕíesek należy raczej potraktować jako poświadczenie rzadkie. Nazwę pies znają również współcześni mieszkańcy Spławia i okolicy. W przeprowadzonych tam badaniach korespondencyjnych okazało się, że nazwę pies uzyskano od przedstawicieli p. II, zaś piesek potwierdziły osoby z p. III.

Niebagatelną rolę odgrywa fakt, że w punkcie 56a (w niedalekiej odległości od Spławia w kierunku północno-wschodnim) odnotowano w AJKLW wyrażenie ṕieseg do butuf oraz podano informację, że „SJP-Dor (Kom. 6-2, s. 352) rejestruje słowo piesek jako człon wyrażenia: Piesek do (od) butów 'rodzaj stołeczka, o który opiera się nogi, aby łatwiej z nich było ściągnąc buty z cholewami" "6. Współcześnie dysponujemy cytatami ze Spławia: Piesek do ściaganio butów oficerek, pies do zdejmowania butów, pies do butów (zapis oryginalny z ankiety, nie zaś zgodny ze stosowaną w Pracowni Dialektologicznej UAM zasadą zapisów tekstów gwarowych; podkreślenia - J.K.) oraz sformułowaniami z innych punktów badawczych: pies (!) od/do butów: MłP: no ... [...] jes ...jes ... pies (!) od butów ... to u nas sie dtugo poniewieroł po dziadku ... oraz MaM: a to jez do tych butów..., MłP: to jes pies do butów ścionganio ... nie ..., SzA: zezuć to buty takie wysokie ... takie oficerki ... to było zezuć ... to mieli takigo psa ... co do ścion ganió ... nie ... - wszystkie odnotowane w Bukówcu Górnym, tj. w południowej Wielkopolsce, podczas gdy w AJKLW podaje się poświadczenie tego wyrażenia ze wschodniej części regionu. Ponadto piesek w znaczeniu 'drewniany przyrząd do zdejmowania butów o długich cholewach' występuje w Moim słowniku gwary pałuckiej, co zgadza się z danymi atlasowymi, jest też znany autorowi Słownika Warmińskiego, choć w słowniku tym nazwa piesek funkcjonuje jako część definicji do hasła parobek, nie zaś jako osobne hasło. Piesek w znaczeniu 'wyzuwacz’ występuje w kartotece SGŚ (Ochaby ciesz), jest również hasłem MSGP - 'przyrząd służący do ściągania butów z cholewami’: Piesek to pozywali - tako deska buła, pod spodkiem troszeczke stojaczka i wyciynte, so se piynte wsadził i buyty scióngnót Granowo n-tom; Mp pn, Maz, Wp.

Nazwa piesek została potwierdzona także w okolicach Krzyszczewa jako jedna z dwóch odnotowanych w najbliżej tej wsi położonym punkcie atlasowym, tj. Oborze, obok nazwy pies. Warto nadmienić, że dla przedstawiciela młodszego pokolenia [SzA] zarówno nazwa jak i desygnat są nieznane.

Interesująca, stara nazwa wyzuwacz została potwierdzona w Jaryszewie; wcześniej notowano ją w AJKLW. Poza tym uzyskano w tym punkcie badawczym poświadczenie: $d r a j-$ fus (obocznie stosowane z wyzuwacz), bez wątpienia germanizm - Dreifuß 'trójnóg'. W SGP PAN odnajdziemy szereg haseł, w których elementem składowym jest cząstka draj-, np. drajbark/ drajcug 'orczyk służący do zaprzęgania trzech koni', drajfałda 'wierzchnie okrycie męskie z rękawami i trzema fałdami z tyłu', drajnoga 'stołek szewski na trzech nogach' itd. Leksem drajfus w SGP PAN występuje w 6 znaczeniach (1. 'żelazna podstawka pod garnki do gotowania', 2. 'podstawka pod blachę do pieczenia ciasta W piekarniku', 3. 'przyrząd w kształcie cyrkla służący do pomiarów w terenie', 4. 'trzy żelazne kopyta szewskie osadzone na jednym trzonie', 5. 'trójnożny przyrząd do obrabiania dyszla', 6. 'sprzęt domowy na trzech nogach, służący do siedzenia; stołek'), z których żadne nie odpowiada 'nazwom przyrządu do ściągania butów z cholewami'. W innych materiałach regionalnych drajfus w omawianym znaczeniu nie występuje.

${ }^{6}$ Kom. 6-2, s. 111. 
Być może drajfus-wyzuwacz wziął swoją nazwę od trójrożnego kształtu deski (głównego elementu tego przyrządu) oraz jego zastosowania - wkładania stopy w wycięcie deski w celu wyjęcia jej z buta (stąd też konotacja dosłowna z niem. Dreifuß: drei 'trzy' i Fuß 'stopa' - człowiek ,zyskuje trzecią stopę” wkładając ją do psa/ pieska/ pomocnika etc.).

Co do formy wyzuwacz, to bez wątpienia jest ona przejrzysta etymologicznie - derywat utworzony formantem -acz od czasownika wyzuwać 'zdejmować'. Jest to forma rodzima, stara. Odnotowana w kartotece SGŚ oraz w kartotece SGP PAN (w tym właśnie znaczeniu: 'przyrząd do zdejmowania butów') - także poza Wielkopolską?

$\mathrm{Z}$ nazw rzadszych należy przywołać tu pozyskane jednorazowo: pomocnik, koń, szczu$d t a$.

Nazwa pomocnik odnotowana w Baranówku i Sowinkach budzi skojarzenie z tradycyjną nazwą na tym obszarze - zanotowaną przez zespół AJKLW - parobek ${ }^{8}$. Można snuć przypuszczenia, że współczesny pomocnik to odpowiednik ówczesnego parobka, który w sensie dosłownym pełnił funkcję pomocniczą w gospodarstwie, zaś w omawianym znaczeniu pomaga zdejmować buty. Przyjmując ten trop za ewentualną drogę ewolucji nazwy, należy stwierdzić, że doszło tu do zmiany formalnej, nie zaś znaczeniowej. Możliwe, że informator specjalnie użył sformułowania pomocnik, a nie tradycyjnego określenia parobek, wyczuwając anachroniczność drugiej nazwy (świadomość językowa badanych osób jest bardzo często zaskakująco wysoka). Mamy zatem poświadczenie jednorazowe, od informatora z p. II (dziś już nieżyjącego), które trudno poddać weryfikacji. Nadmienię, że hasło parobek w 3. znaczeniu 'urządzenie do zdejmowania długich butów' odnajdujemy w słowniku Władysława Brzezińskiego (autor odwołuje się w haśle do niem. der Stiefelknecht - 'parobek').

Ciekawostką jest pojedyncze poświadczenie nazwy koń w Bukówcu Górnym uzyskane od kobiety ur. w 1934 roku [ŚlZ]; informatorka przypisuje tę nazwę swojemu ojcu. Określenie $k^{y} y n ́$ (tj. koń) zostało wcześniej odnotowane przez zespół AJKLW w punkcie 89. Gorzyce Wielkie-Topola Mała pod Ostrowem; nie odnotowano go wówczas dla miejscowości 74. Bukówiec Górny, ani też współcześnie u innych bukówczan.

Podobnie interesująca wydaje się - również jednokrotnie zanotowana (obocznie do piesek) - nazwa koziołek (Spławie). Być może określenie to jest reminiscencją kuezy, którą to nazwę notuje się jednokrotnie w AKLW dla punktu 81 (tj. Goszczanów-Poniatów) położonym na wschód od Kalisza.

Badania terenowe są niekiedy źródłem poświadczeń nieprawdziwych. $\mathrm{Z}$ dużą dozą prawdopodobieństwa poświadczeniem takim jest nazwa $s z c z u d ł a$ zapisana w Baranówku i Sowinkach. Nazwa ta wydaje się stworzoną przez informatora dla potrzeb prowadzonej rozmowy, tym bardziej, że dostępne źródła gwarowe jej nie potwierdzają, ani też nie pojawiła się wśród innych badanych na tym obszarze informatorów.

Stosunkowo często wśród indagowanych osób pytanie o 'przyrząd do zdejmowania butów z cholewami' powodowało chwilę zastanowienia, by w końcu niejako drogą dedukcji dojść do podania konkretnej nazwy lub pozostawienia odpowiedzi na pytanie w postaci

\footnotetext{
${ }^{7}$ Interesujące, acz nieweryfikowalne, jest poświadczenie z Palędzia (gm. i pow. Poznań): kozioł [SzM] mężczyzna ur. 1952.

${ }^{8}$ Warto zauważyć, że w zachodniej, południowo-zachodniej oraz w kierunku północnym regionu odnotowano w AJKLW nazwę pachołek - informacja istotna w kontekście dalszych analiz i rozważań.
} 
dość ogólnej - przez nazwanie owego przedmiotu po prostu deska, często w złożeniu kilkuwyrazowym funkcjonującym jako forma zleksykalizowana, np. SzA: sie wkładało ... $w$ takiegó ... specjalnie z deski zrobióne ... i ... potym tak ... cióngło sie po ty desce $i$ óne sie schowaty ..., RaA: tych ... tych ... tych ... szczudła czy jakoś ... te deski takie mieli ...

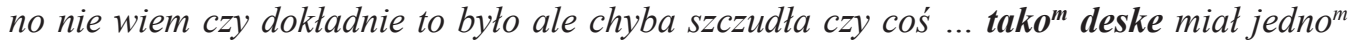
nogo ${ }^{m}$ nadepnot ... tu korkiem zahoczyt ... tag jag miat wycie te ... i ścion gnot ... albo tak ... chyba że ... nie wiem doktadnie ale ... bodajże to szczudta byty takie ....

Niektórych tradycyjnych nazw z badanych punktów nie udało się współcześnie potwierdzić, np. ryčuška, kobyukka.

Dla nazwy ryčuška (w AJKLW podane dla punktu badawczego 74. Bukówiec Górny) nie uzyskano jak dotąd potwierdzenia, czego powodem może być fakt, że nazwa ta nazbyt kojarzy się ze znaną powszechnie w Wielkopolsce ryczka, czyli 'stołkiem', którym 'przyrząd do zdejmowania butów z cholewami’ przecież nie jest.

Co do nazwy kobytka (odnotowanej w AJKLW w okolicach Spławia), to wśród współcześnie przebadanych osób, nie została ona poświadczona. Jest to nazwa występująca w: MSGP w znaczeniu 3. 'przyrząd służący do zdejmowania butów z cholewami' Maz, Wp pd-wsch. Mimo braku tego poświadczenia i przy uwzględnieniu dotychczas uzyskanych i wyżej opisanych nazw, można uznać, że 'przyrząd do zdejmowania butów z cholewami’ ma wiele określeń o charakterze zoonimicznym, z których większość oceniana jest jako poświadczenia incydentalne; wyjątkiem jest pies/piesek, który wykazuje znamiona powszechności na obszarze Wielkopolski.

'Przyrząd do zdejmowana butów z cholewami' jest desygnatem funkcjonującym w świadomości najstarszych mieszkańców wielkopolskich wsi. Wśród osób z pokolenia średniego (tu: p. III) znajomość - zarówno przedmiotu, jak i nazwy - wyraźnie zaczyna się zacierać, część pytanych informatorów nie potrafiła udzielić odpowiedzi, np. z Bukówca Górnego [BaK], [MaM], z Branówka i Sowinek [MiJ], [MiG] czy z Krzyszczewa [SzA]. Coraz częściej ten swoisty zabytek znany jest z lokalnych izb pamięci lub dzięki opowieściom osób starszych. Dla informatorów z przedziału pokoleniowego II nazwy te stanowią zasób słownictwa biernego, wymierającego.

Opis nazw starych desygnatów uwydatnia rolę i wartość prowadzonych współcześnie badań terenowych. Świadomość zaniku pewnych grup słownictwa (a i zaniku desygnatów), sprawia, że konieczność zebrania jak największej liczby poświadczeń od najstarszych mieszkańców wsi jest tym bardziej nagląca.

\section{Bibliografia}

AGM-8: Kowalska Anna, Strzyżewska-Zaremba Alina, Atlas gwar mazowieckich, t. 2-10, Wrocław - Warszawa - Kraków 1972-1992.

AGP-2: Dejna Karol, Gala Sławomir, Zdaniukiewicz Alojzy, Czyżewski Feliks, Atlas gwar polskich.

Tom 2. Mazowsze, Warszawa2002. 
AJKLW-6: Sobierajski Zenon, Burszta Józef (red.), Atlas języka i kultury ludowej Wielkopolski, t. 6: Włókiennictwo - Odzież - Obuwie, cz. 1. Mapy 513-575, cz. 2. Wykazy i komentarze do map 513-575, Wrocław - Warszawa - Kraków 1991.

Barska-Antos Danuta, Stownictwo Warmii i Mazur. Odzież, [w:] Witold Doroszewski (red.) Studia Warmińsko-Mazurskie, t. 12, Wrocław - Warszawa - Kraków 1980.

B in k o w s k i Mirosław, Mój stownik gwary pałuckiej, Żnin 2011.

B r z z i ńs k i Władysław, Słownictwo krajniackie. Słownik gwary wsi Podróżna w Złotowskiem,

t. 1-5, Wrocław 1987-2009.

Dragan Zofia, Woźna Dominika, Budz Jan, Kowalczyk Julian, Łukuś Elżbieta, Ma j e r c zak Józef, M i k c k a Zofia, Co wieś, to inna pieśń. Słownik gwary Bukówca Górnego w Wielkopolsce i regionu Spisza w Małopolsce, Kraków 2014.

MSGP: Wr o n i c z Jadwiga (red.), Mały słownik gwar polskich, Kraków 2009.

SGP PAN: Pracownia (Zakład) Dialektologii Polskiej IJP PAN, (oprac.), Stownik gwar polskich PAN, t. 1, Mieczysław Karaś (red.), t. 2-5, Jerzy Reichan, Stanisław Urbańczyk, (red.), t. 6, z. 1-4, Joanna Okoniowa, Jerzy Reichan (red.), t. 7-8, z 1-4, Joanna Okoniowa, Jerzy Reichan, Barbara Grabka, (red.), Wrocław - Kraków 1977-2013.

SGŚ: Wyderka Bogusław (red.), Stownik gwar śląskich, t. 1-13, Opole 2000-2012.

Sierociuk Jerzy, Założenia metodologiczne badań języka wsi, „Poznańskie Spotkania Językoznawcze”, t. 11, red. Z. Krążyńska i Z. Zagórski, Poznań 2003, s. 130-136.

S i e r o c i u k Jerzy, Kwestionariusz do badania stownictwa gwarowego. IV. Praca (wersja elektroniczna dostępna w Pracowni Dialektologicznej UAM).

S t e ffe n Wiktor, Słownik warmiński, Wrocław 1984.

JUSTYNA KOBUS

The names of the old wooden instrument to remove the top boots 30 years after Atlas language and folk culture of Wielkopolska (with examples from selected villages in Wielkopolska)

\section{Summary}

The article describes the names of the old wooden instrument to remove the top boots from Greater Poland. the author confronted contemporary materials with the old material, especially as described in the Atlas of language and folk culture of Greater Poland and other available publications. Article is part of a series of studies entitled 30 years after Atlas language and folk culture of Greater Poland, which is realized in the Section of Dialectological AMU.

Keywords: dialect, generation variation, old designatum 